\title{
ANALISIS KELAYAKAN USAHATANI JAMBU GONDANGMANIS DI DESA GONDANGMANIS KECAMATAN BANDARKEDUNGMULYO JOMBANG
}

\author{
Ramadhan Galang Pribadi ${ }^{1}$, Mochammad chumaidi ${ }^{2}$ \\ 1, 2 Progam Studi Agribisnis, Fakultas Pertanian Universitas KH. Abdul Wahab \\ Hasbullah \\ ${ }^{1}$ Email : ramadhanpribadi26@gmail.com
}

\begin{abstract}
The Jombang Regency area has one of the superior fruit products, known as guava gondangmanis (Syzygium Malaccense). Gondangmanis guava is usually planted by the community around the house or on garden land. The purpose of this study was to determine the income of gondangmanis guava farmers and to test using the feasibility criteria for farming to determine whether the gondangmanis guava farming was financially profitable. The eligibility criteria used the calculation of the $R / C$ ratio, B/C ratio, NPV, and IRR. This study uses quantitative methods, with the data used are primary data and secondary data. Primary data were obtained at the research location by means of interviews and direct observation. While secondary data obtained from books, previous thesis and research journals. Determination of respondents by using purposive sampling method which considers that the respondent has a garden with a minimum of 10 trees, which is 10 farmer respondents. This study calculates the results of farmers' farming from 2018 to 2020. The results of the study show that the average income earned by farmers in 2018 is Rp. 2, 786,633, in 2019 it is Rp. 5,604,833, and in 2020 it is Rp. 5,681 .583. And the results of the feasibility analysis of farming when viewed from the $R / C$ ratio $4.0 \mathrm{~B} / \mathrm{C}$ ratio 3.0 with an NPV value of $R p .11,894,941$, and IRR $59.45 \%$. With the criteria of $R / C$ ratio $>1, B / C>1, N P V>0$, and $I R R>$ loan interest rate. With an interest rate of $8.25 \%$, it means that Gondangmanis guava farming in Gondangmanis Village is feasible to continue.
\end{abstract}

Keyword : Farming, Income, Feasibility of Farming

\begin{abstract}
ABSTRAK
Diwilayah Kabupaten Jombang memiliki salah satu produk buah unggulan, yang dikenal dengan jambu gondangmanis (Syzygium Malaccense). Jambu gondangmanis biasa ditanam oleh masyarakat pada sekitar rumah maupun pada lahan kebun. Tujuan dari penelitian ini adalah untuk mengetahui pendapatan petani jambu gondangmanis dan menguji dengan menggunakan kriteria kelayakan usahtani untuk mengetahui apakah usahatani jambu gondangmanis ini menguntungkan secara finansial. Kriteria kelayakan menggunakan perhitungan $R / C$ rasio, B/C rasio, NPV, dan IRR. Penelitian ini menggunakan metode kuantitatif, dengan data yang digunakan adalah data primer dan data sekunder. Data primer di peroleh pada lokasi penelitian dengan cara wawancara dan observasi langsung. Sedangkan data sekunder diperoleh dari buku-buku, skripsi terdahulu dan jurnal-jurnal penelitian. Penentuan responden dengan
\end{abstract}


menggunakan metode purposive sampling yang mempertimbangkan bahwa responden memiliki kebun dengan minimal terdapat 10 pohon yaitu berjumlah 10 petani responden. Penelititan ini menghitung hasil usahatani petani dari tahun 2018 hingga 2020. Hasil dari penelitian menunjukan rata-rata pendapatan yang diperoleh petani di tahun 2018 sebesar Rp.2.786.633, di tahun 2019 sebesar Rp.5.604.833, serta di tahun 2020 sebesar Rp 5.681.583. Dan hasil dari analisis kelayakan usahatani bila di tinjau dari nilai $R / C$ rasio $4,0 \mathrm{~B} / \mathrm{C}$ rasio 3,0 dengan nilai NPV Rp. 11.894.941, dan IRR 59,45\%. Dengan kriteria nilai $R / C$ rasio $>1, B / C>$ 1, NPV >0, dan IRR > suku bunga pinjaman. Dengan besar suku bunga 8,25\%, artinya usahatani jambu gondangmanis di Desa Gondangmanis layak untuk dilanjutkan.

Kata kunci: Usahatani, Pendapatan, Kelayakan Usahatani

\section{PENDAHULUAN}

Indonesia adalah negara dengan iklim tropis yang memungkinkan berlangsungnya berbagai musim buah, sayuran, dan bunga sepanjang tahun. Di samping itu, keanekaragaman komoditas tanaman hortikultura memungkinkan untuk tumbuh baik di dataran tinggi atau dataran rendah. Komoditas hortikultura khususnya sayuran dan buah-buahan memegang peran penting dalam keseimbangan pangan yang dikonsumsi, sehingga harus tersedia setiap saat dalam jumlah yang cukup, mutu yang baik, aman dikonsumsi, harga yang terjangkau, serta dapat diakses oleh seluruh lapisan masyarakat

Salah satu tanaman hortikultura di Indonesia adalah jambu air. Menurut survei Pertanian Hortikultura yang mencakup data produksi buah-buahan dan sayuran tahunan per kecamatan di seluruh wilayah Indonesia, jambu air menghasilkan 182.908 ton untuk seluruh wilayah Indonseia pada tahun 2020. Lebih sedikit dibandingkan dengan tanaman hortikultural lainnya seperti pisang yang mencapai 8 juta ton di tahun 2020. Dan untuk wilayah Jawa Timur produksi jambu air mencapai 33.730 ton pada tahun 2020 (BPS, 2020). Sedangkan menurut Badan Pusat Statistik Kabupaten Jombang produksi jambu air pada tahun 2018 hingga 2020 adalah mencapai 7.701 Kwintal ditahun 2018, 7.206 di tahun 2019 dan 9.797 ditahun 2020. Dengan penghasil terbanyak di daerah Kecamatan Bandarkedungmulyo yang mencapai 4.593 kwintal.

Salah satu jenis jambu air yang jarang diketahui orang adalah jambu bol (sunda) atau jambu darsono (jawa) dengan nama latin Syzygium Malaccense, buah ini biasa ditanam dipekarangan, koleksi tanaman hias, atau sebagai pohon pelindung. Jambu darsono ini merupakan salah satu tanaman yang berpotensi untuk meningkatkan pendapatan petani. Salah satunya adalah di daerah Kabupaten Jombang Jawa Timur.

Jambu darsono atau yang lebih di kenal dengan jambu gondangmanis ini untuk daerah Kabupaten Jombang memiliki rasa dan ukuran yang khas dibandingkan dengan daerah-daerah lainnya oleh karena itu disebut dengan jambu gondangmanis. Jambu gondangmanis merupakan produk unggulan di Desa Gondangmanis, Kecamatan Bandarkedungmulyo yang memiliki harga sekitaran Rp. 8.000 - Rp. 12.000 /kilonya. Bila satu pohon jambu gondangmanis rata-rata 
menghasilkan $200 \mathrm{Kg} /$ tahun maka untuk satu pohon mendapatkan 2.000.000 $\mathrm{Rp} / \mathrm{Kg}$. Hal ini yang menjadi bahan pertimbangan bagi peneliti untuk meneliti tentang kelayakan usahatani jambu gondangmanis di Desa Gondangmanis Kecamatan Bandarkedungmulyo Kabupaten Jombang.

\section{METODE PENELITIAN}

Penelitian ini menggunakan penelitian metode kuantitatif. Metode kuantitatif merupakan metode penelitian yang berdasarkan pada filsafat positivisme, yang digunakan untuk meneliti pada populasi atau sampel tertentu, pengumpulan data menggunakan instrumen penelitian, analisis data bersifat kuantitatif / statistik, dengan tujuan untuk menggambarkan hasil penelitian (Sugiyono, 2018)

Populasi dalam penelitian ini adalah seluruh petani jambu gondangmanis yang berada di Desa Gondangmanis. Jumlah populasi sebanyak 288 orang petani dan jumlah sampel yang di tetapkan sebanyak 10 orang dengan menggunaan teknik penarikan sampel menggunakan non probability sampling yaitu teknik pengambilan sampel yang tidak memberikan kesempatan yang sama pada anggota populasi untuk menjadi sampel. Dan dengan menggunakan metode purpsive sampling yaitu metode yang penetuan sampelnya dengan pertimbangan tertentu. Dengan mempertimbangkan bahwa petani memiliiki kebun jambu gondangmanis dengan minimal 10 pohon.

Data yang di gunakan Data primer adalah data yang diperoleh dari lokasi penelitian, dari hasil observasi, dan wawancara dengan petani sampel yang telah dipersiapakan koesioner terlebih dahulu. Data sekunder adalah data yang diperoleh dari buku-buku, instansi/lembaga, literatur/artikel dan jurnal yang berkaitan dengan penelitian yang dilakukan

Lokasi penelitian ini di laksanakan di Desa Gondangmanis, Kecamatan Bandar kedungmulyo, Kabupaten Jombang. Pemilihan lokasi penelitian ini dilakukan sengaja (purposive sampling) dengan pertimbangan bahwa jambu gondangmanis merupakan produk unggulan desa.

Teknik pengumpulan data yang digunakan dalam penelitian ini adalah dengan menggunakan koesioner, observasi serta wawancara terbuka. Wawancara terbuka adalah wawancara yang bebas dimana peneliti tidak menggunakan pedoman wawancara yang sistematis untuk pengumpulan data. Pedoman yang digunakan berupa garis-garis besar dari permasalahan yang akan ditanyakan.

\section{ANALISIS PENDAPATAN USAHATANI}

Usahatani Menurut Soekartawi, (1995) dalam Saeri (2018) Ilmu usahatani biasanya juga diartikan sebagai ilmu yang mempelajari bagaimana cara mengalokasikan sumberdaya yang tersedia secara efektif dan efisisen dengan harapan pada waktu tertentu akan memperoleh keuntungan yang tinggi. Sehingga usahatani merupukan upaya petani dalam mengolah sumberdaya sekitar untuk mengahasilkan keuntungan.

Didalam usahatani juga tak lepas dari biaya produksi, penerimaan serta pendapatan yang di peroleh petani. Biaya produksi Biaya produksi merupakan biaya yang terjadi untuk mengolah bahan baku menjadi produk jadi yang siap 
untuk dijual (Mulyadi, 2012). Biaya produksi yang di gunakan terdiri dari biaya tetap dan biaya variabel. Biaya tetap menurut Hasa (2018) biaya yang secara tetap dibayar atau dikeluarkan oleh produsen atau pengusaha dan besarnya tidak dipengaruhi oleh tingkat output. Yang termasuk kategori biaya tetap dalam penelitian ini adalah penyusutan alat dan sewa lahan. Biaya variabel adalah biaya yang besar kecilnya sangat tergantung pada skala produksi. Yang termasuk biaya variabel antara lain : benih, pupuk, obat, upah tenaga kerja.

Penerimaan dalam usahatani adalah seluruh pemasukan yang diterima dari kegiatan produksi yang menghasilkan uang tanpa dikurangi dengan total biaya - biaya yang dikeluarkan (Husni \& Maskan, 2014) atau dengan kata lain perkalian antara jumlah produksi dengan harga jual. Sedangkan menurut Sutrisno (2019) pendapatan merupakan selisih penerimaan dan biaya yang dikeluarkan. Pendapatan mempunyai fungsi untuk digunakan memenuhi kebutuhan sehari hari dan melanjutkan kegiatan usahatani. Besarnya pendapatan usahatani dapat digunakan menilai keberhasilan petani dalam mengelola usaha taninya.

Analisis pendapatan menurut (Ramadhani dkk., 2018) dapat di tulis sebagai berikut:

a. Total biaya produksi :

$\mathrm{TC}=\mathrm{FC}+\mathrm{VC}$

Keterangan :

$\mathrm{FC}=$ fixed cost (Biaya tetap)

$\mathrm{VC}=$ variable cost (Biaya variabel)

b. Penerimaan

$T R=P \times Q$

Keterangan:

$\mathrm{P}=$ Price (harga)

$\mathrm{Q}=$ Quantity (kuantitas)

c. Pendapatan:

$\pi=\mathrm{TR}-\mathrm{TC}$

Keterangan:

$\pi=$ Pendapatan

$\mathrm{TR}=$ total penerimaan

$\mathrm{TC}=$ total biaya

\section{KELAYAKAN USAHATANI}

Kelayakan usahatani digunakan untuk menilai dan mengukur suatu usaha yang sedang dijalankan layak atau tidak dilakukan maka ada beberapa kriteria yang perlu diperhatikan sebagai berikut: 
a. Revenue Cost Ratio (R/C Rasio)

Revenue/Cost Ratio adalah merupakan perbandingan antar total penerimaan dan total biaya di mana penerimaan dengan total biaya dengan rumus sebagai berikut :

$$
R / C=\frac{T R}{T C}
$$

Dimana:

$\mathrm{R} / \mathrm{C}=$ Revenue Cost Ratio

$\mathrm{TR}=$ Penerimaan usahatani $(\mathrm{Rp})$

$\mathrm{TC}=$ Biaya total usahatani $(\mathrm{Rp})$

Kriteria:

$\mathrm{R} / \mathrm{C}>1$, usahatani layak diusahakan

$\mathrm{R} / \mathrm{C}<1$, usahatani tidak layak diusahakan

$\mathrm{R} / \mathrm{C}=1$, usahatani dikatakan impas (Mahmud, 2020)

b. Benefit Cost Ratio (B/C Rasio)

$\mathrm{B} / \mathrm{C}$ ratio merupakan rasio perbandingan keuntungan dengan biayabiaya yang digunakan dalam merealisasikan perencanaan pendirian dan mengoperasikan suatu usaha untuk melihat manfaat yang didapat oleh proyek dengan satu rupiah pengeluarann (Mahmud, 2020). Rumus yang digunakan sebagai berikut :

$\mathrm{B} / \mathrm{C}$ rasio $=\pi / \mathrm{TC}$

Dimana:

$\mathrm{B} / \mathrm{C}=$ Benefit/Cost Ratio

$\pi=$ Pendapatan $(R p)$

$\mathrm{TC}=$ Total Biaya $(\mathrm{Rp})$

\section{Dengan Kriteria}

Nilai $B / C=1$, Maka usaha jeruk lemon impas

Nilai $B / C>, 1$ Maka Usaha jeruk lemon layak

Nilai B/C < 1 Maka usaha tidak layak (Sipayung, 2019)

\section{c. Net Present Value (NPV)}

Net Present Value (NPV) adalah suatu alat analisis untuk menguji kelayakan dari suatu investasi. NPV adalah nilai sekarang dari arus pendapatan yang ditimbulkan oleh investasi pada tingkat bunga tertentu. Suku bunga yang di gunakan sebesar $8,25 \%$ (SBDK riet BRI 2021) serta rumus NPV adalah sebagai berikut: 


$$
\mathrm{NPV}=\sum_{t=0}^{n}(\text { Net Benefit })(D F)
$$

Keterangan:

NPV $=$ Net Present Value

$\mathrm{DF}=$ suku bunga yang berlaku

Dengan ketentuan:

Jika NPV > 0, berarti usaha tersebut layak dilakukan atau dilanjutkan

Jika NPV < 0, maka usaha tersebut tidak layak dilakukan atau dilanjutkan

Jika NPV $=0$, manfaat yang diperoleh hanya cukup untuk menutup biaya yang dikeluarkan (Fika et al., 2017).

\section{d. Internal rate of return (IRR)}

Internal rate of return (IRR) adalah untuk mencari suatu tingkat bunga yang akan menyamakan jumlah nilai sekarang dari penerimaan yang diharapkan yang diterima dengan jumlah nilai sekarang dari pengeluaran untuk investasi. Dengan kata lain, IRR adalah discount rate yang menjadikan NPV sama dengan nol. Rumus yang digunakan:

$\operatorname{IRR}=i_{1}+\frac{N P V}{(N P V 1-N P V 2)} x\left(i_{2}-i_{1}\right)$

Dengan ketentuan:

Jika IRR > tingkat bunga, maka usaha tersebut layak untuk diusahakan atau dilanjutkan.

Jika IRR = tingkat bunga, maka biaya yang dikeluarkan sama dengan keuntungan yang didapatkan.

Jika IRR < tingkat bunga, maka usaha tersebut tidak layak untuk diusahakan atau dilanjutkan(Admojo, 2017).

\section{DEFINISI VARIABEL}

Variabel penelitian merupakan suatu karakteristik atau atribut yang menjadi fokus penelitian yang dapat berubah-ubah atau bervariasi sesuai kondisi objek atau subjek penelitian. Variabel-variabel yang dilibatkan dalam penelitian ini serta sifat hubungan antara variabel-variabel tersebut perlu di definisikan secara operasional.

1. Jambu gondangmanis merupakan salah satu jenis jambu jamaika yang tumbuh tersebar di Desa Gondangmanis dan menjadi komodita unggulan desa.

2. Lokasi usahatani adalah tempat yang digunakan oleh petani untuk melakukan usahatani jambu gondangmanis.

3. Responden adalah petani jambu gondangmanis yang diwawancarai untuk memperoleh data. 
4. Tenaga kerja adalah orang yang membantu dalam produksi usaha jambu gondangmanis dengan di beri upah.

5. Usahatani jambu gondangmanis adalah suatu usaha pertanian yang dilakukan oleh petani diatas sebidang tanah yang ditanam tanaman jambu gondangmanis.

6. Sarana produksi adalah bahan yang digunakan sebagai input dalam proses produksi usaha dan menghasilkan suatu output.

7. Biaya produksi adalah seluruh biaya keluaran yang dikeluarkan oleh petani yang terdiri dari biaya variabel dan biaya tetap.

8. Produksi adalah hasil yang di keluarkan oleh petani dari kegiatan usahatani yaitu berupa jambu gondangmanis yang siap jual

9. Harga jual adalah besarnya nilai jambu gondangmanis yang dibebankan oleh konsumen.

10. Penerimaan usahatani jambu gondangmanis merupakan sejumlah uang yang diterima oleh petani dengan mengkalikan biaya produksi dengan harga jual.

11. Pendapatan adalah penerimaan yang diperoleh petani dengan mengurangi antara total penerimaan dengan total biaya produksi.

12. Kelayakan usahatani adalah perbandingan antara total penerimaan dengan total biaya produksi yang digunakan untuk menentukan layak atau tidak layak suatu usahatani jambu gondangmanis.

13. Kriteria kelayakan merupakan instrumen yang digunakan untuk mengetehui kelayakan finansial usahatani yang terdiri dari $\mathrm{R} / \mathrm{C}$ rasio, $\mathrm{B} / \mathrm{C}$ ratio, NPV, , dan IRR.

\section{HASIL DAN PEMBAHASAN}

\section{A. Keadaan umum responden}

1. Umur

Responden merupakan seseorang yang dapat dipilih untuk menjadi narasumber dalam mencari sebuah informasi. Dengan ini responden di pilih merupakan masyarakat petani jambu di Desa Gondangmanis. Responden penelitian ini terdiri dari 10 petani jambu gondangmanis. Dapat dlihat pada tabel 1.

Tabel 1. Umur Petani Responden

\begin{tabular}{ccc}
\hline & Umur \\
\hline Keterangan & Jumlah (jiwa) & Presentase $\%$ \\
\hline $50-65$ & 7 & $70 \%$ \\
\hline $66-80$ & 3 & $30 \%$ \\
\hline Jumlah & 10 & $100 \%$ \\
\hline
\end{tabular}

Sumber : Data Diolah 2021

Di dalam Tabel 1 umur petani responden antara 50-65 tahun berjumlah 7 jiwa dan antara 66-80 tahun berjumlah 3 jiwa. Peneliti menemukan bahwa petani jambu gondangmanis memiliki umur yang telah lanjut usia hal ini di karenakan para responden telah cukup lama tinggal di Desa Gondangmanis serta telah lama bertani yang lain sehingga tidak menutup kemungkinan petani di Desa 
Gondangmanis memiliki tanaman tahunan sebagai salah satu alternatif di waktu bertani tanaman semusim lainnya.

\section{Pekerjaan}

Di ketahui bahwa Dari 10 responden tersebut pekerjaan utama adalah petani dengan jumlah 5 orang buruh tani 4 orang dan selain petani 1 orang. Bila diliat pada tabel 2 pekerjaan utama responden berupa petani dan buruh petani yang mana memang pekerjaan umum yang dilakukan masyarakat Desa Gondangmanis petani. Dan menurut pengamatan langsung yang dilakukan oleh peneliti jika masyarakat memiiliki pekerjaan utama yang lainnya tetap melakukan pekerjaan petani walau pun sebagai sampingan.

Tabel 2. Pekerjaan Umum Petani Responden

\begin{tabular}{ccc}
\hline & Pekerjaan utama & \\
\hline Ket. & Jumlah (jiwa) & Presentase \% \\
\hline Petani & 5 & $50 \%$ \\
\hline Buruh tani & 4 & $40 \%$ \\
\hline Lain-lain & 1 & $10 \%$ \\
\hline Jumlah & 10 & $100 \%$
\end{tabular}

\section{Sumber : Data Diolah 2021}

\section{Luas Lahan}

Diketahui juga pada tabel 3 bahwa luas lahan petani responden di Desa Gondang manis adalah dari 0,04 hingga 0,1 sebanyak 6 orang serta dari 0,21 hingga 0,28 sebanyak 4 orang. Lahan yang dimiliki petani jambu gondangmanis merupakan lahan kebun yang terdapat pada sekitar perkarangan rumah milik sendiri. Hal ini memang sangat memungkinkan disebabkan pada umumnya masyasrakat di desa gondangmanis masih memiliki lahan yang luas di sekitar rumah atau pun lahan kosong di dekat rumah.

Tabel 3. Keadaaan Umum Petani Responden

\section{Luas lahan Milik}

\begin{tabular}{ccc}
\hline Ket. & Jumlah (jiwa) & Presentase $\%$ \\
\hline $0,04-0,1$ & 6 & $60 \%$ \\
\hline $0,21-0,28$ & 4 & $40 \%$ \\
\hline Jumlah & 10 & $100 \%$
\end{tabular}

Sumber : Data Diolah 2021

\section{ANALISIS PENDAPATAN USAHATANI}

\section{A. Biaya Produksi}

Biaya variabel. Biaya tetap adalah biaya yang umumnya selalu tetap, bahkan dimasa sulit. Biaya tetap yang terdapat pada usahatani jambu 
gondangmanis adalah penyusutan alat yang terdiri dari spayer, arit, cangkul, serta orok.

Pada penyusutan alat, perhitungan dilakukan dengan rumus penyusutan alat metode garis lurus, yaitu nilai awal dikurang nilai akhir dibagi dengan nilai ekonomis alat dikali umur pakai alat dikali jumlah alat, dimana pada penggunaan cara perhitungan ini diasumsikan bahwa pada usia ekonomis tertentu alat dianggap sudah tidak memiliki nilai sisa. Untuk penentuan usia ekonomis didasarkan atas ketahanan alat dan penggunaan alat. Sehingga rata-rata peyusutan alat per tahunnya adalah Rp. 107.167.

Lahan yang digunakan petani jambu gondangmanis merupakan milik pribadi yang berada di sekitaran rumah, tetapi karena usahatani bersifat komersil maka biaya sewa tetap dianggarkan kan. Biaya sewa yang berlaku di daerah peneliti pertahun adalah Rp 3.000.000/Ha/tahun. Sehingga rata - rata biaya sewa lahan adalah sebesar Rp. 369.600. Untuk rata - rata Total biaya tetap yang harus dikeluarkan petani jambu gondangmanis adalah sebesar Rp. 476.767.

Biaya Variabel merupakan biaya yang dapat berubah-ubah setiap tahunnya. Biaya variabel meliputi:

1. Biaya Tenaga kerja.

Pada umumnya tenaga kerja yang di lakukan petani responden manis di Desa Gondangmanis adalah dengan melakukan kegiatan sendiri atau di bantu oleh saudara, istri/suami, maupun anaknya. Hal ini telah menjadi hal biasa yang dilakukan oleh petani jambu gondangmanis Karena memang pada dasarnya pekerjaan utamanya petani maupun buruh tani oleh karena itu ketika saat proses merawat pohon jambu gondangmanis tidak terlalu repot serta perwatannya mudah maka tidak perlu banyak tenaga kerja sehingga petani biasa melakukan sendiri. Diketahui bahwa rata - rata biaya yang di keluarkan petani untuk tenaga kerja pada tahun 2018 adalah Rp 532.000, di tahun 2019 sebesar Rp 690.000 dan pada tahun 2020 rata - rata per petani adalah Rp 670.000 .

\section{Biaya Pupuk}

Penggunaan pupuk yang lebih mengarah kepada sistem pertumbuhan tanaman jambu tidak dilakukan pada setiap tahun sedangkan pupuk yang lebih mengarah kepada buah di lakukan sebelum buah menjadi besar. Pemupukan pada system pertumbuhan dilakukan saat bibit baru di tanam. Kemudian kurang lebih 2-3 tahun menggunakan pupuk kembali. Pupuk yang di gunakan antara lain NPK, Za, KCL, KNO, Grandasil B serta pupuk kompos. Biaya rata-rata yang digunakan adalah sebesar Rp 248.000 pada tahun 2018, Rp 348.200 pada tahun 2019 serta pada tahun 2020 jumlah biaya yang digunakan sebesar Rp 350.750.

\section{Obat}

Obat yang digunakan berupa pestisida yang di fungsikan untuk mengatasi hama pada tanaman jambu gondangmanis. Seperti hama penggerek batang, dan lalat buah, serta semut yang menggangu pertumbuhan buah jambu gondangmanis. Obat yang digunakan antara lain seperti obat perangsang buah, 
dangke, distar dan untuk lalat buah. Biaya penggunaan obat rata-rata pada tahun 2018 adalah Rp. 113.900, di tahun 2019 sebesar Rp.112.200, serta di tahun 2020 sebesar Rp.128.900.

Sehingga total rata-rata biaya variabel (tenaga kerja, pupuk, serta obat) yaitu pada tahun 2018 sebesar Rp. 908.900, di tahun 2019 sebesar Rp. 1.166 .400 serta di tahun 2020 sebesar Rp. 1.167.650..

Dan untuk biaya total produksi adalah dengan menjumlahkan biaya tetap dan biaya variabel. Sehingga rata-rata total biaya produksi di tahun 2018 sebesar Rp.1.369.367, ditahun 2019 sebesar Rp. 1.637.167, serta ditahun 2020 adalah sebesar Rp. 1.626.417.

\section{B. Analisis Penerimaan}

Penerimaan merupakan jumlah produksi di kali dengan harga produksi. Untuk di daerah penelitian harga jual jambu gondangmanis per kilo pada tahun 2018 kisaran $\mathrm{Rp} 8.000 / \mathrm{kg}$ dan pada tahun berikutnya mengalami kenaikan harga pada kisaran Rp $12.000 / \mathrm{kg}$. Petani Jambu Gondangmanis rata-rata panen sebenyak 2 kali dalam setahun bahkan bisa 3 kali. Panen buah terjadi pada bulan Maret sedangkan panen kedua terjadi pada bulan Juli/Agustus. Sehingga ratarata Total penerimaan petani jambu gondangmanis pada tahun 2018 sebanyak Rp. 4.156.000, di tahun 2019 sebanyak Rp. 7.242.000 dan di tahun 2020 sebanyak Rp. 7.308.000.

\section{Analisis Pendapatan}

Pendapatan petani jambu gondangmanis merupakan hasil bersih keuntungan yang di peroleh petani setelah penerimaan di kurangi dengan biaya produksi. Dengan demikian rata-rata jumlah pendapatan petani jambu gondangmanis pada tahun 2018 sebesar Rp. 2.786.633, di tahun 2019 sebesar Rp.5.604.833, serta di tahun 2020 sebesar Rp 5.681.583. Rincian usahatani dapat diliat pada tabel 4 .

\section{Analisis Kelayakan Usahatani}

Analisis kriteria investasi dalam usahatani juga melibatkan discount factor karena analisis kelayakan berkaitan dengan time value of money (nilai waktu uang). Sehingga discount factor digunakan untuk menghitung nilai uang pada saat sekarang. Analisis kelayakan dalam pembahasaan ini menggunakan nilai discount factor saat suku bunga sebesar $8,25 \%$ (SBDK ritel Bank BRI). Hasil analisisi kelayakan usahatani dapat di lihat pada tabel 4.

Tabel 4. Rincian rata-rata Pendapatan Usahatani Jambu Gondangmanis

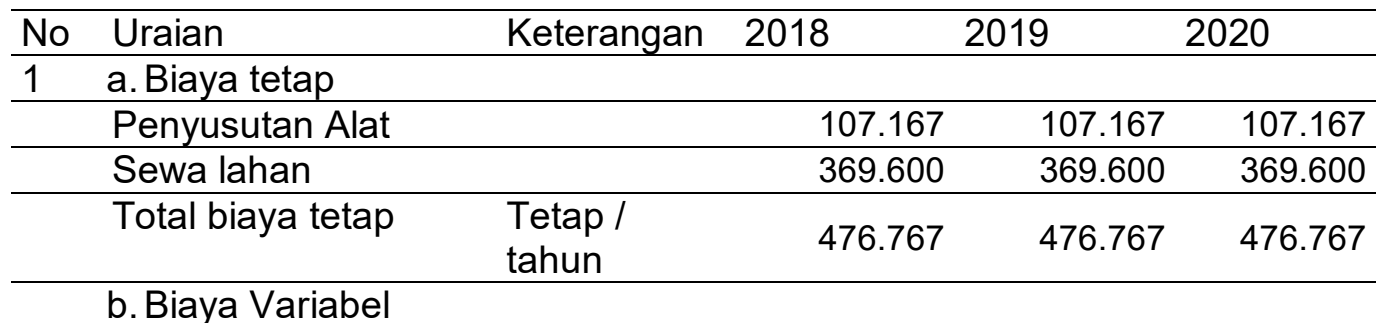




\begin{tabular}{|c|c|c|c|c|c|}
\hline & \multicolumn{2}{|l|}{ Tenaga kerja } & 532.000 & 690.000 & 670.000 \\
\hline & \multicolumn{2}{|l|}{ Pupuk } & 248.000 & 348.200 & 350.750 \\
\hline & \multicolumn{2}{|l|}{ Obat } & 113.900 & 122.200 & 128.900 \\
\hline & Total biaya variabel & $\begin{array}{l}\text { Berubah/ } \\
\text { tahun }\end{array}$ & 893.900 & 1.160 .400 & 1.149 .650 \\
\hline & \multicolumn{2}{|c|}{$\begin{array}{l}\text { c. Total biaya produksi Tahun } \\
(\mathrm{a}+\mathrm{b})\end{array}$} & 1.369 .367 & 1.637 .167 & 1.637 .167 \\
\hline 2. & \multicolumn{5}{|l|}{$\begin{array}{l}\text { Penerimaan }(C)= \\
(P . Q)\end{array}$} \\
\hline & \multicolumn{2}{|l|}{ Harga $(P)$} & 8.000 & 12.000 & 12.000 \\
\hline & \multirow[t]{2}{*}{ Total produksi $(\mathrm{Q})$} & $\begin{array}{l}\text { Musim/ } \\
\text { tahun }\end{array}$ & 609,5 & 725,5 & 609 \\
\hline & & & 4.156 .000 & 7.242 .000 & 7.308 .000 \\
\hline 3 & $\begin{array}{l}\text { Pendapatan = C - } \\
(\mathrm{a}+\mathrm{b})\end{array}$ & Tahun & 2.786 .633 & 5.604 .833 & 5.681 .583 \\
\hline
\end{tabular}

Sumber : Data Diolah 2021.

Analisis kelayakan usahatani jambu gondangmanis dilakukan untuk mengetahui kelayakan usahatani yang sedang dilkukan oleh petani. Untuk mengetahui kelyakan usahatani digunakan kriteria kelayakan usahatani yaitu $R / C$ Rasio, B/C Rasio, NPV, serta IRR.

Tabel 5. Hasil Kelayakan Usahatani Jambu Gondangmanis

\begin{tabular}{ccc}
\hline Indikator Kelayakan & Nilai & Kriteria \\
\hline R/C Rasio & 4,0 & Layak \\
\hline B/C Rasio & 3,0 & Layak \\
\hline NPV & 11.894 .941 & menguntungkan \\
\hline IRR & $59,45 \%$ & Layak
\end{tabular}

Sumber : Data Diolah 2021

Dari Tabel 5 dapat di ketahui bahwa nilai $R / C$ rasio sebesar 4,0 yang berarti lebih dari 1 sehingga artinya setiap pengeluaran Rp. 100,-, memberikan penerimaan sebesar Rp. 400 maka dapat dikatakan usahatani layak untuk dilanjutkan. Sedangkan pada B/C rasio memperoleh nilai sebesar 3,0 . Bila B/C rasio $>1$, artinya setiap biaya produksi yang dikeluarkan petani sebesar Rp. 100,, maka diperoleh keutungan sebesar Rp. 300 menunjukan bahwa usahatani jambu gondangmanis layak (menguntungkan).

Analisis kelayakan usahatani bila di liat dari nilai NPV sebesar Rp. 11.894.941, yang berarti petani jambu gondangmanis akan memperoleh keuntungan pada tingkat bunga $8,25 \%$ adalah sebesar Rp. 11.894.941. Jika mengacu pada ketentuan NPV, bila NPV lebih dari 0 maka usaha tersebut layak di lanjutkan. Oleh karena itu nilai NPV usahatani pada jambu gondangmanis lebih dari 0 maka usaha tersebut layak di lanjutkan. 
Dan nilai yang diperoleh dari perhitungan IRR yaitu $59,45 \%$, yang berarti tingkat bunga bank maksimum yang mampu di bayar oleh petani responden sebesar $59,45 \%$ sehingga petani lebih untung atau lebih baik menginvestasikan modalnya dalam bentuk usahatani jambu gondangmanis dibanding dengan menanamkan modalnya ke bank yang hanya mendapatkan bunga sebesar $8,25 \%$. Dengan demikian dapat dikatakan usahatani jambu gondangmanis layak dilanjutkan karena nilai IRR lebih besar dari suku bunga pinjaman bank.

\section{KESIMPULAN}

Jambu gondangmanis merupakan sejenis dengan jambu darsono dan jambu bol jamaika. Jambu godangmanis asli tumbuh di Desa Gondangmanis serta memiliki ciri khas berwarna merah kehitam-hitaman serta daging tebal dan manis. Rata-rata penerimaan yang diperoleh oleh petani jambu gondangmanis dengan rata-rata 2 kali musim panen pada tahun 2018 adalah sebanyak Rp.4.156.000, di tahun 2019 sebanyak Rp. 7.242.000 dan di tahun 2020 sebanyak Rp.7.308.000. Dengan rata-rata pendapatan pada tahun 2018 sebesar Rp.2.786.633, di tahun 2019 sebesar Rp.5.604.833, serta di tahun 2020 sebesar Rp 5.681.583.Diliat dari nilai $\mathrm{R} / \mathrm{C}$ rasio $4,0 \mathrm{~B} / \mathrm{C}$ rasio 3,0 dengan nilai NPV Rp. 11.894.941, dan IRR $59,45 \%$. Dimana nilai $R / C$ rasio $>1, B / C>1$, NPV $>0$, dan $I R R>$ suku bunga pinjaman, artinya usahatani jambu gondangmanis di Desa Gondangmanis layak untuk dilanjutkan.

Usahatani jambu gondangmanis mempunyai peluang besar untuk di kembangkan lebih lanjut baik secara ekonomi maupun menjadi objek wisata sehingga memiliki keuntungan yang besar untuk meningkatkan pendapatan rumah tangga petani maupun desa. Serta perlu adanya perhatian dan dukungan dari pemerintah setempat agar usahatani yang di kelola petani dapat lebih baik lagi dan menjadi produk unggulan desa yang terkenal.

\section{DATAR PUSTAKA}

Admojo, A.B.T. 2017. Analisis Kelayakan Finansial Dan Startegi Penembangan Agroindustri Formula Organik Blontong CV. Putra Harapan Jaya Di Kabupaten Lumajang. Skripsi. Universitas Jember.

BPS 2020. Produksi Tanaman Buah-buahan 2020. Badan Pusat Statistik. Tersedia di https://www.bps.go.id/indicator/55/62/1/produksi-tanaman-buahbuahan.html [Accessed 14 Juli 2020].

BPS 2021. Jombang Dalam Angka 2021. Jombang: Badan Pusat Statistik Kabupaten Jombang.

Fika, P.W.M., Suwandari, A. \& Hartadi, R. 2017. Analisis Kelayakan Finansial Dan Kontribusi Pendapatan Terhadap Pendapatan Rumah Tangga Pembudidaya Ikan Lele Dumbo. Agritrop : Jurnal IImu-IImu Pertanian (Journal of Agricultural Science), 14(2): 199-207.

Hasa, S. 2018. Analisis Pendapatan Usahatani Padi Sawah di Desa Leppangan Kecamatan Pitu Riase Kabupaten Sidrap. Skripsi. Muhammadiyah 
Makassar.

Husni, A.K.H. \& Maskan, A.F. 2014. Analisis Finansial Usahatani Cabai Rawit (Capsicum frutescens L) Di Desa Purwajaya Kecamatan Loa Janan. Agrifor: Jurnal IImu Pertanian dan Kehutanan, 13(1): 49-52.

Mahmud, T.H. 2020. Analisis Usahatani Cengkeh di Desa Watampanua Kecamatan Angkona Kabupaten Luwu Timur. Universitas Muhammdiyah Makassar.

Moh. Saeri 2018. Usahatani dan Analisinya. Malang: Universitas Wisnuwardhana Malang Press.

Mulyadi 2012. Akutansi Biaya. 5 ed. Yogyakarta: STIM YKPN.

Ramadhani, F., Zakiah \& Fajri 2018. Analisis Pendapatan dan Kelayakan Usahatani Timun Suri di Gampong Babah Jurong Kecamatan Kuta Baro Kabupaten Aceh Besar. Jurnal IImiah Mahasiswa Pertanian unsyiah, 3(2): 256-263.

Sipayung, Y.A. 2019. Analisis Pendapatan Usahatani Jeruk Lemon(Studi kasus : Desa Sekoci,Kecamatan Besitang Kabupaten langkat). Universitas Muhammadiyah Sumatera Utara.

Soekartawi 1995. Analisis Usahatani. Jakarta: Universitas Indonesia Press.

Sugiyono 2018. Metode Penelitian Kuantitatif. Bandung: Alfabeta.

Sutrisno 2019. Analisis Breakeven Poin Budidaya Kangkung Dalam Meningkatkan Pendapatan Masyarakat Di Desa Kedungmakam Kecamatan Jatirogo Tuban. Universitas Bojonegoro. 